\title{
Síndrome de Wünderlich por rotura de quiste renal en paciente tratado con dicumarínicos
}

\author{
Herranz Fernández LM, Arellano Gañán. R, Garrido Abad P, Jiménez Gálvez MI, \\ Bocardo Fajardo Gloria, Fernández González I.
}

Servicio de Urología. Hospital Universitario de la Princesa. Madrid.

Actas Urol Esp. 2008;32(8):861

\begin{abstract}
T a hemorragia renal espontánea de etiología no traumática o Uíndrome de Wúnderlich es una patología poco frecuente y grave. Su etiología más importante es la tumoral, siendo los quistes renales y las discrasias sanguíneas una rara causa de este cuadro. La prueba más útil para visualizar inicialmente el sangrado es la ecografía; aunque la mejor prueba para evaluar a estos pacientes es la TAC. El tratamiento debe ser lo más conservador posible, usando si fuera necesario la arteriografía con embolización de los vasos responsables de la hemorragia.

Varón de 78 años con antecedentes de HTA en tratamiento médico; síntomas del tracto urinario inferior en tratamiento con doxazosina 4mg/día; multiquistosis renal bilateral; anticoagulado con acenocumarol por fibrilación auricular; insuficiencia renal crónica; operado de hernia inguinal bilateral y de enfermedad de Dupuytren. Acude al Servicio de Urgencias por presentar dolor súbito en fosa lumbar izquierda y vómitos. A la exploración el paciente está estable y presenta una masa dolorosa en hemiabdomen izquierdo con puño-percusión renal positiva en ese lado. $\mathrm{Al}$ ingreso en Urgencias presenta un análisis de sangre normal. Radiografía de abdomen: borramiento de la parte superior de la línea del psoas izquierdo. Ecografía abdominal: quistes hepáticos. Riñón derecho con quistes corticales simples. Riñón izquierdo con aumento del tamaño con mala diferenciación corticomedular con masa central de $67 x 65 \mathrm{~mm}$. En región posteroinferior nódulo sólido de $38 \times 32 \mathrm{~mm}$ que parece corresponder a un quiste complicado o a una neoplasia. No líquido perirrenal, ni intraabdominal.

El paciente ingresa en el Servicio de Urología para estudio y tratamiento con el diagnóstico de hemorragia renal espontánea izquierda por quiste complicado o por neoplasia.
\end{abstract}

A las pocas horas del ingreso el paciente presenta aumento del dolor lumbar. Se realiza TAC abdominal urgente donde se observan quistes en riñón derecho e hígado. Desestructuración del riñón izquierdo por masa de $11 \mathrm{~cm}$ que parece corresponder a un hematoma por rotura de un quiste renal sin poder descartar la existencia de una neoplasia (Fig. 1). Dada la situación se decide transfundir plasma y administrar vitamina $\mathrm{K}$ para mejorar la coagulación y realizar arteriografía del riñón dañado.

Se realiza arteriografía renal izquierda visualizándose un punto de sangrado activo que se emboliza con éxito.

El paciente evoluciona favorablemente tras la embolización y 7 días más tarde se realiza otro TAC abdominal donde se objetiva hematoma perirrenal izquierdo evolucionado con extensión similar al estudio previo y donde no se objetiva la existencia de neoplasia renal. Quistes simples renales bilaterales y hepáticos (Fig. 2). Dada la situación basal del enfermo, la buena respuesta al tratamiento y el estudio radiológico, se decide realizar revisiones periódicas en consulta externa con TAC abdominal.

El paciente se revisó durante 6 años, dándose de alta tras este periodo. Durante todo este tiempo no se ha objetivado neoplasia renal y en el último TAC se visualizan múltiples quistes hepáticos y renales bilaterales y una trabeculación de la grasa del espacio perirrenal, junto al polo inferior izquierdo en relación con el sangrado previo (Fig. 3).

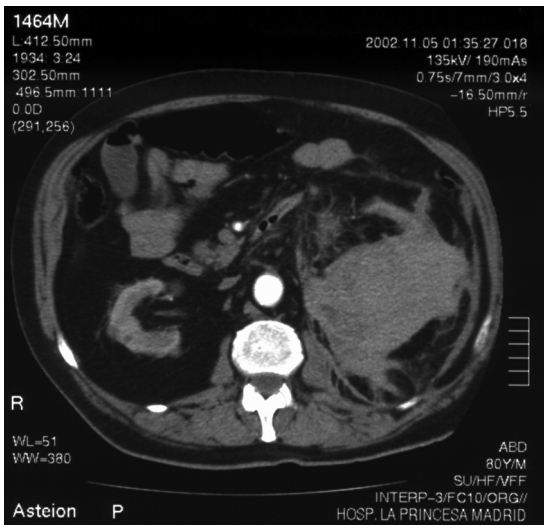

FIGURA 1. TAC abdominal. Quistes corticales en riñón derecho. Hematoma de 11 cm en la cara posterior del riñón izquier do que desplaza anteriormente dicho riñón.

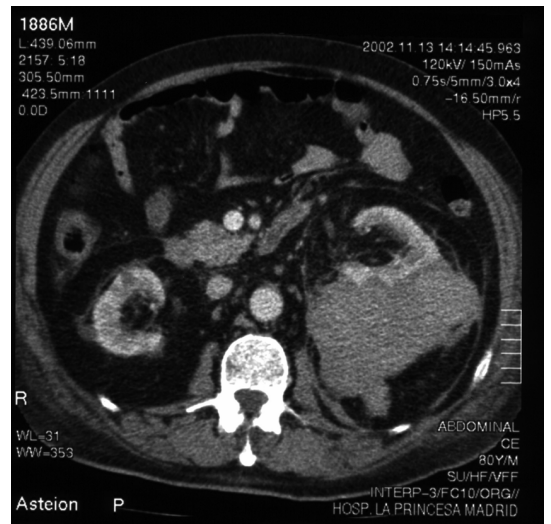

FIGURA 2. TAC abdominal: Quistes corticales en riñón derecho. Hematoma en cara posterior del riñón izquierdo con buena función del mismo. Quistes corticales en riñón izquierdo.

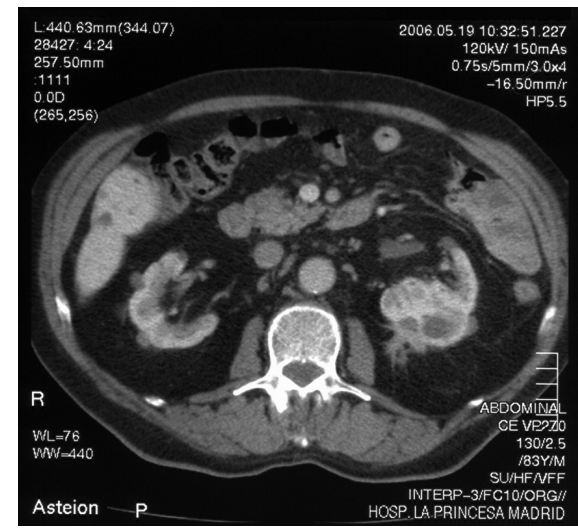

FIGURA 3. TAC abdominal: Quistes corticales bilaterales. Trabeculación del tejido del espacio perirrenal posterior del riñón izquierdo. 